\title{
BILÍNGUE, EU? REPRESENTAÇÕES DE SUJEITOS BILÍNGUES FALANTES DE PORTUGUÊS E INGLÊS
}

\author{
Bilingual, me? Representations of bilingual speakers of Portuguese and \\ English
}

\section{Antonieta Heyden MEGALE- PUC-SP ${ }^{1}$}

\begin{abstract}
RESUMO: Nunca antes os termos bilinguismo e educação bilíngue estiveram em tamanha evidência na sociedade brasileira. O país assiste a um grande aumento na chegada de imigrantes de nacionalidades diversas. Somando-se a isso, não se pode ignorar os impactos da globalização que, como argumentam McGrew e Held (1992), conectam comunidades em novas combinações de espaço-tempo. Frente a esses dados, o objetivo deste trabalho é o de discutir as representações de sujeitos falantes de português e inglês sobre o que é ser bilíngue e o que é bilinguismo. Os relatos analisados foram obtidos a partir da pergunta: Você se considera bilíngue? Por quê?. Neste sentido, propomos uma interpretação discursiva desses relatos, apoiada em autores que versam sobre representações sociais, como Moscovici (2003) e Jodelet (2001) e teóricos que discorrem sobre bilinguismo e bilingualidade como Maher (2007), Hamers e Blanc (2000), Heye (2003) e García (2009). A análise dos dados apontou para uma dificuldade dos sujeitos desta pesquisa de se denominarem bilíngues. Notou-se que vigora, ainda, no Brasil, o ideal monolíngue. Dessa forma, ser bilíngue exige definições e justificativas como se observou entre as narrativas dos participantes, que tentam buscar, na teoria, explicações para a aceitação de sua condição.
\end{abstract}

PALAVRAS-CHAVE: Bilinguismo; Bilíngue; Bilingualidade; Representações.

ABSTRACT: Never before have the terms bilingualism and bilingual education been in great evidence in the Brazilian society. The country is witnessing a large increase in the arrival of immigrants of various nationalities. Adding to this, one cannot ignore the impacts of globalization which, as argued by Held and McGrew (1992), connect communities in new combinations of space-time. Given these data, the objective of this paper is to discuss the representations of bilingual speakers of Portuguese and English about what to be bilingual is and what bilingualism is. The reports analyzed were obtained from the question: Do you consider yourself bilingual? Why? In this way, we propose a discursive interpretation of these reports, supported by authors who deal with social representations, such as Moscovici (2003) and Jodelet (2001) and authors who study bilingualism and bilinguality such as Maher (2007), Hamers and Blanc (2000), Heye (2003) and Garcia (2009). Data analysis pointed to a difficulty of the individuals of this research to define themselves as bilingual. It was noted that the ideal of monolingualism is still present in Brazil. Thus, to be bilingual requires definitions and justifications as observed among the narratives of the participants, who try to seek, in the theory, explanations for the acceptance of their condition.

KEY WORDS: Bilingualism; Bilingual; Bilinguality; Representations.

\footnotetext{
${ }^{1}$ Mestre em Línguistica Aplicada pela PUC-SP. É coordenadora de Língua Inglesa da Escola Brasileira Israelita Chaim Nachman Bialik. Atua como professora no curso de extensão Bilinguismo: Revisão de teorias e análise de dados da COGEAE/PUC-SP e na pós graduação Didática para Educação Bilíngue do Instituto Singularidades.
} 


\section{SITUANDO ESTE TRABALHO}

Embora haja uma vasta gama de contextos em que se utilizam mais de uma língua, os estudos sobre contextos bi/multilíngues ainda são incipientes no Brasil. Isso parece ocorrer porque, como Cavalcanti (1999) argumenta, o mito do monolinguismo é fortemente enraizado em nosso país. Dessa forma, há um apagamento do fato de que no Brasil há “cerca de 203 línguas, a saber: pelo menos 170 línguas indígenas, 30 línguas de imigrantes, 2 línguas de sinais (Língua Brasileira de Sinais - LIBRAS - e a língua dos Urubu-Kaapor) e evidentemente, a língua portuguesa" (MAHER, 1997, p.22).

Somando-se a isso, não se pode ignorar os impactos da globalização que, como argumentam McGrew e Held (1992), conectam comunidades em novas combinações de espaço-tempo, tornando o mundo mais interconectado. Outro fator desencadeante do interesse por línguas estrangeiras no Brasil foi à ascensão econômica da classe C, o que representa mais de 90 milhões de brasileiros com acesso à educação e ao mundo de trabalho. Com isso, a procura por escolas de idiomas aumentou consideravelmente, assim como o número de brasileiros que têm a possibilidade de estudar no exterior ou que opta por colégios internacionais ou bilíngues.

Frente a estes dados, o objetivo deste trabalho é o de discutir as representações de sujeitos falantes de português e inglês sobre o que é ser bilíngue e o que é bilinguismo. O corpus desta pesquisa foi obtido através das respostas à pergunta "Você se considera bilíngue? Por quê?” dadas, por escrito, por nove bilíngues simultâneos ${ }^{2}$ e nove sequenciais, durante o ano de 2011.

Propomos uma interpretação discursiva de recortes, realizados a partir desses relatos, apoiada em autores que versam sobre representações sociais como Moscovici (2003) e Jodelet (2001) e teóricos que discorrem sobre bilinguismo e bilingualidade como Maher (2007), Hamers e Blanc (2000), Heye (2003) e García (2009).

Este artigo está organizado em cinco seções. Nas duas primeiras, apresentamos a base teórica utilizada para a análise de dados deste estudo. Na primeira, discorremos acerca do conceito de representação social a partir de Moscovici (2003) e Jodelet (2001). A seguir, discutimos sobre concepções de bilinguismo e de sujeito bilíngue

\footnotetext{
${ }^{2}$ Entende-se, neste trabalho, por bilíngues simultâneos, indivíduos que adquiriram as duas línguas ao mesmo tempo, sendo expostos às mesmas desde o nascimento. Os bilíngues sequenciais, por sua vez, adquiriram a língua estrangeira após terem adquirido a base linguística da língua materna (HAMERS; BLANC, 2000).
} 
partindo de concepções unidimensionais como as de Bloomfield (1935), Macnamara (1967), Barker Prys (1998) e Li Wei (2000). Discorremos também sobre concepções teóricas que contemplam em sua definição de bilinguismo, tanto a dimensão linguística como a não linguística, como Maher (2007), Hamers e Blanc (2000) e Heye (2003), que trabalham com o conceito de bilingualidade, e García (2009) que advoga a favor de uma visão heteroglóssica de língua. Por fim, introduzimos a perspectiva derridiana (2001), que discute a construção de próteses por bilíngues. Na seção seguinte, em que há a coleta do corpus e a metodologia de análise, descrevemos o contexto de pesquisa e a seleção dos dados utilizados, assim como os procedimentos de análise empregados. A seguir, expomos a análise do corpus e, finalmente, na seção Tessituras Finais, tecemos os comentários finais sobre a temática discutida.

Vale ressaltar que as representações sociais sobre bilinguismo desempenham um papel primordial na constituição identitária de indivíduos que se deparam com situações de contato de línguas, como é o caso dos sujeitos desta pesquisa. Não podemos esquecer que as representações sociais, por se tratarem de saberes produzidos na sociedade, são capazes de produzir marcas, positivas ou negativas, no indivíduo ou no grupo em que ele se insere e, com isso, afetam a forma como o indivíduo se percebe e percebe o grupo de que faz parte.

\section{REPRESENTAÇÕES SOCIAIS: ALGUMAS APROXIMAÇÕES}

O conceito de Representação Social surgiu do trabalho de Serge Moscovici, intitulado La Psychanalyse, son image et son public (1961), que se ocupava do estudo pioneiro sobre a difusão da psicanálise em diferentes âmbitos, de sua apropriação e de transformação para outras funções sociais no pensamento popular parisiense da referida época.

Para fazer frente a tal perspectiva, Moscovici buscou referência na obra de Durkheim (1895/1982), que preconizava a explicação sociológica dos fatos sociais, mais especificamente, em seu conceito de Representações Coletivas. Entendendo a sociedade como uma realidade em si, Durkheim (1947, apud MOSCOVICI, 1978) entende as representações coletivas como categorias que são produzidas e que coletivamente formam a bagagem cultural de uma sociedade. Entretanto Moscovici (2003) adota o termo "social" e não "coletivo" a fim de enfatizar a qualidade dinâmica 
das representações sociais, em contraposição ao caráter mais fixo que elas tinham em Durkheim. Contudo, o autor explica que as duas palavras são, muitas vezes, usadas como sinônimas e que prefere social, pois essa palavra remete a "uma ideia de diferenciação, de redes de pessoas e suas interações" (MOSCOVICI, 2003, p. 348).

Em relação às diferenças dos conceitos de representações apresentado por Durkheim e Moscovici, Duveen (2003), na introdução do livro Representações Sociais - investigações em psicologia social (MOSCOVICI, 2003), esclarece que enquanto Durkheim vê as representações coletivas como formas estáveis de compreensão coletiva, Moscovici concentra-se na exploração da variação e da diversidade das ideias coletivas nas sociedades modernas, o que gera uma heterogeneidade de representações. Perante essas diversidades, segundo Duveen (2003), surgem os pontos de tensão e é, ao redor desses pontos de clivagem, que se caracterizam pela falta de sentido, que novas representações emergem com o objetivo de reestabelecer um sentido de estabilidade. Moscovici (2003) explica que as representações são criadas por pessoas ao se comunicarem e interagirem dentro de seus grupos, mas alerta para o fato de que, uma vez criadas, "elas adquirem vida própria, circulam e dão oportunidade para o surgimento de novas representações” (MOSCOVICI, 2003, p.41). É por isso que, segundo o autor, para se compreender uma representação é necessário resgatar aquela, ou aquelas, das quais ela nasceu, sendo que quanto mais sua origem é esquecida mais fossilizada a representação se torna.

A partir dos estudos de Moscovici sobre as representações sociais, muitos teóricos e pesquisadores vêm enriquecendo esse campo em diferentes áreas de pesquisa das Ciências Humanas e Sociais. Denise Jodelet, principal colaboradora de Moscovici, contribui significantemente para a sistematização e o aprofundamento teórico das representações sociais. O conceito de representações sociais, proposto por Jodelet (2001), é definido como uma forma de conhecimento, socialmente elaborada e partilhada e que contribui para a construção de uma realidade comum a um conjunto social. De acordo com a autora, as representações sociais são saberes de senso comum ou ainda saberes ingênuos e naturais cujos conteúdos manifestam a operação de processos generativos e funcionais socialmente marcados. O estudo de tais fenômenos, como enfatiza a autora, possibilita o desvelamento de diversos elementos que, tantas vezes, foram estudados isoladamente: “[...] informativos, cognitivos, ideológicos, normativos, crenças, valores, atitudes, opiniões, imagens etc.” (JODELET, 2001, p.21). 
Somando-se a isso, Moscovici (2003) explica que a função primeira das representações sociais é tornar o não familiar em familiar. E isso significa que as representações criadas são sempre o resultado do esforço constante de se tornar comum e real, algo que é incomum ou não familiar. Segundo o autor, supera-se o problema integrando-o em nosso mundo mental e físico, que é, assim, enriquecido e transformado. Esse processo, prossegue o autor, reestabelece um sentido de continuidade no grupo e no sujeito que se encontrava ameaçado pela descontinuidade e falta de sentido. É por isso que, ao estudar uma representação, de acordo com Moscovici (2003), deve-se descobrir a característica não familiar que a motivou e o momento exato em que ela emerge na esfera social.

Além disso, as representações sociais possuem outras duas funções. Em primeiro lugar, elas convencionalizam objetos, pessoas ou acontecimentos e os localizam em uma determinada categoria, colocando-os gradualmente como um modelo de determinado tipo partilhado por um grupo de pessoas. Em relação a essa função das representações, o autor alerta que nenhuma mente está livre dos efeitos dos condicionamentos anteriores que lhes são impostos por suas representações, linguagem e cultura. Retomando essas condições, podemos inferir, primeiramente, que os pensamentos dos sujeitos se organizam conforme um sistema que está condicionado pelas representações. Em segundo lugar, de acordo com Moscovici (2003), as representações são prescritivas, uma vez que se impõem sobre os sujeitos devido à combinação de uma estrutura que está presente antes de se começar a pensar e de uma tradição que decreta o que deve ser pensado. Um aspecto importante ainda a mencionar são as representações que são transmitidas de geração a geração e representam "uma estratificação na memória coletiva e uma reprodução na linguagem que, invariavelmente, reflete um conhecimento anterior e que quebra as amarras da informação presente" (MOSCOVICI, 2003, p. 37).

Desse modo, posteriomente, pretendemos discutir as noções de bilinguismo, bilingualidade e sujeito bilíngue, uma vez que a partir de estudos teóricos, como os de Grosjean (1982), constata-se que falar duas línguas pode esconder conflitos identitários difíceis de serem explicados ou equacionados. 


\section{ALGUMAS CONSIDERAÇÕES SOBRE AS NOÇÕES DE BILINGUISMO, BILINGUALIDADE E SUJEITO BILÍNGUE}

A noção de bilinguismo tornou-se cada vez mais ampla e difícil de conceituar a partir do século XX. Na visão popular, ser bilíngue é o mesmo que ser capaz de falar duas línguas perfeitamente; essa é também a definição empregada por Bloomfield (1935), que define bilinguismo como o controle nativo de duas línguas. Opondo-se a esta visão que inclui apenas bilíngues perfeitos, Macnamara (1967) propõe que um indivíduo bilíngue é alguém que possui competência mínima em uma das quatro habilidades linguísticas (falar, ouvir, ler e escrever) em uma língua diferente de sua língua nativa.

Entre estes dois extremos, encontram-se outras definições, como, por exemplo, a definição proposta por Barker e Prys Jones (1998), que levantam algumas questões para a classificação de indivíduos bilíngues:

- Devem-se considerar bilíngues somente indivíduos fluentes nas duas línguas?

- São considerados bilíngues apenas indivíduos com competência linguística equivalente nas duas línguas?

- Proficiência nas duas línguas deve ser o único critério para a definição de bilinguismo, ou o modo como essas línguas são utilizadas também deve ser levado em consideração?

De forma semelhante a Barker e Prys (1998), Li Wei (2000) argumenta que o termo bilíngue basicamente pode definir indivíduos que possuem duas línguas, entretanto, deve-se incluir, entre estes, indivíduos com diferentes graus de proficiência nessas línguas e que, muitas vezes, fazem uso de três, quatro ou mais línguas.

Diferentemente dos teóricos citados, Maher (2007) contempla em sua definição de bilinguismo tanto a dimensão linguística como uma dimensão não linguística:

O bilíngue - não o idealizado, mas o de verdade - não exibe comportamentos idênticos na língua X e na língua Y. A depender do tópico, da modalidade, do gênero discursivo em questão, a depender das necessidades impostas por sua história pessoal e pelas exigências de sua 
comunidade de fala, ele é capaz de se desempenhar melhor em uma língua do que na outra '- e até mesmo de se desempenhar em apenas uma delas em certas práticas comunicativas (MAHER, 2007, p. 73).

Essa visão multidimensional apresentada por Maher (2007) pode ser alinhada com a proposta de Hamers e Blanc (2000), que distinguem o bilinguismo em duas modalidades: a bilingualidade e o bilinguismo. Os autores definem a bilingualidade como um estado psicológico de um indivíduo que tem acesso a mais de um código linguístico como meio de comunicação. Por outro lado, o bilinguismo, segundo os autores, refere-se ao estado de uma comunidade linguística na qual duas línguas estão em contato e são utilizadas para a interação. Heye (2003) acrescenta que a bilingualidade pode ser entendida como os diferentes estágios de bilinguismo, pelos quais os indivíduos, portadores da condição de bilíngue, passam em sua trajetória de vida. De acordo com Heye (2003, p. 33-34), “esses estágios são vistos como processos situacionalmente fluídos e definem, de forma dinâmica a bicompetência linguística, comunicativa e cultural nas diferentes épocas e situações de vida."

Corroborando essa linha de pensamento, Hamers e Blanc (2000) analisam seis dimensões ao definir o bilinguismo individual ou bilingualidade. A saber:

1. competência relativa; 2. organização cognitiva; 3 . idade de aquisição; 4. presença ou não de indivíduos falantes da língua estrangeira no ambiente em questão; 5. status das duas línguas envolvidas; 6. identidade cultural. Dentre as seis dimensões propostas, enfocaremos, neste estudo, quatro $^{3}$ delas: (i) a competência relativa, (ii) a idade de aquisição, (iii) o status das línguas e (iv) a identidade cultural, que descrevemos a seguir:

A dimensão relacionada à competência relativa prioriza a relação entre as duas competências linguísticas. Obtêm-se, assim, as definições de bilinguismo balanceado e bilinguismo dominante. Considera-se bilíngue balanceado o indivíduo que possui competência linguística equivalente em ambas línguas. Por bilíngue dominante, entende-se o indivíduo que possui competência maior em uma das línguas em questão.

\footnotetext{
${ }^{3}$ Escolhemos quatro dimensões das seis propostas pelo autor, pois as respostas obtidas dentre os sujeitos desta pesquisa trazem dados que podem teoricamente ser discutidos a luz dessas dimensões. As duas dimensões não empregadas, organização cognitiva e presença ou não de indivíduos falantes da língua estrangeira no ambiente em questão, não nos forneceram subsídios teóricos para a discussão dos dados desta pesquisa.
} 
A segunda dimensão empregada neste estudo está de acordo com a idade de aquisição da língua estrangeira. São identificados: o bilinguismo infantil, adolescente ou adulto. $\mathrm{O}$ bilinguismo infantil subdivide-se: em bilinguismo simultâneo e bilinguismo sequencial. No bilinguismo simultâneo, a criança adquire as duas línguas ao mesmo tempo, sendo exposta às mesmas desde o nascimento. Por sua vez, no bilinguismo sequencial, a criança adquire a língua estrangeira ainda na infância, mas após ter adquirido as bases linguísticas da língua materna. Quando a aquisição da língua estrangeira ocorre durante o período da adolescência, conceitua-se esse fenômeno como bilinguismo adolescente e por bilinguismo adulto, entende-se a aquisição da língua estrangeira que ocorre durante a idade adulta.

A terceira dimensão, aqui utilizada, dá-se de acordo com o status atribuído a estas línguas na comunidade em questão. A partir disso, o indivíduo desenvolverá formas diferenciadas de bilinguismo. A primeira delas é o bilinguismo aditivo, na qual as duas línguas são suficientemente valorizadas no desenvolvimento cognitivo da criança e a aquisição da língua estrangeira ocorre, consequentemente, sem perda ou prejuízo da língua materna. No entanto, na segunda forma de aquisição, denominada bilinguismo subtrativo, a língua materna é desvalorizada no ambiente infantil, gerando desvantagens cognitivas no desenvolvimento da criança e, neste caso, durante a aquisição da língua estrangeira, ocorre perda ou prejuízo da língua materna.

Finalmente, a quarta dimensão, que empregamos neste estudo, trata de como indivíduos bilíngues podem ser diferenciados em termos de identidade cultural, obtendo-se bilíngues biculturais, monoculturais, aculturais e desculturais.

Como bilinguismo bicultural, entende-se o indivíduo bilíngue que se identifica positivamente com os dois grupos culturais e é reconhecido por cada um deles. No bilinguismo monocultural, o indivíduo bilíngue identifica-se e é reconhecido culturalmente apenas por um dos grupos em questão. Deve ser ressaltado que um indivíduo bilíngue pode ser fluente nas duas línguas, mas se manter monocultural. Já acultural é considerado o indivíduo que renuncia sua identidade cultural relacionada à sua língua materna e adota valores culturais associados ao grupo de falantes da língua estrangeira. Finalmente, o bilinguismo descultural dá-se quando o indivíduo bilíngue desiste de sua própria identidade cultural, mas falha ao tentar adotar aspectos culturais do grupo falante da língua estrangeira. 
García (2009), por sua vez, questiona o proposto por Hamers e Blanc (2000), ao afirmar que os modelos de bilinguismo aditivo e subtrativo têm, em seu início e em seu fim, sujeitos monolíngues, uma vez que nomeiam uma língua claramente como a primeira e a língua adicional como a segunda, criando duplos monolíngues e, dessa forma, não respondendo mais à grande complexidade linguística do século. A autora argumenta que o bilinguismo aditivo, por exemplo, enxerga as práticas linguísticas do sujeito a partir de uma visão monoglóssica e cria, dessa maneira, espaços monolíngues protegidos, uma vez que defende a separação completa das línguas.

A autora propõe que os conceitos de bilinguismo aditivo e subtrativo sejam reconsiderados a partir de uma visão heteroglóssica, que não vê essas línguas como separadas completamente, e, sim, considere que o sujeito se constitui na imbricação de ambas. A partir disso, García (2009) propõe os conceitos de bilinguismo recursivo e dinâmico. O recursivo, segundo a autora, refere-se a casos nos quais o bilinguismo é desenvolvido após as práticas linguísticas de uma comunidade terem sido suprimidas. Nesses casos, o desenvolvimento da língua materna da comunidade não pode ser considerado uma simples adição que tem início em um ponto monolíngue, uma vez que a língua ancestral continua a ser utilizada em cerimônias tradicionais e por alguns membros da comunidade em diferentes graus. De acordo com García (2009), o bilinguismo, nesses casos, é recursivo porque alcança novamente algumas práticas linguísticas ancestrais, enquanto elas são redirecionadas para novas funções e, com isso, ganham ímpeto para serem projetadas no futuro.

O bilinguismo dinâmico, por sua vez, refere-se a práticas linguísticas que são múltiplas e se ajustam ao terreno multilíngue e multimodal do ato comunicativo. García (2009) salienta que o bilinguismo dinâmico se refere aos variados graus de habilidade e usos de múltiplas práticas linguísticas necessárias para se cruzar fronteiras físicas e virtuais.

Apesar de as concepções de bilinguismo apontarem para diversos elementoschave, como grau de competência linguística, identidade cultural e a sensação ou não de pertencimento, não conseguem explicar o conflito/sofrimento experimentado por diversos sujeitos em sua condição bilíngue. É, nesse ponto, que julgamos valiosa a introdução da perspectiva derridiana, tal como se apresenta no ensaio "O Monolinguismo do Outro" (2001). Nessa obra, que não trata exclusivamente da questão 
do bilinguismo, Derrida formulou alguns princípios gerais da relação entre ser humano, língua e identidade.

Derrida (2011) não faz uma distinção categórica entre as línguas materna e estrangeira, no sentido de que seria possível atribuir ao falante nativo uma determinada identidade ou um determinado conhecimento linguístico que seria vedado ao falante supostamente não nativo. Na ótica derridiana, há apenas línguas, das quais o falante pode apropriar-se em maior ou menor grau, mas que ele nunca é capaz de possuir por completo. Em consequência, também, não há como sustentar os critérios que costumam ser usados para descrever a condição bilíngue apresentada anteriormente.

Nessa ótica, não se distingue o bilinguismo de outras formas de domínio linguístico, dado que todos os falantes são considerados indivíduos plurilíngues e que desejam alcançar um idioma absoluto que se apresenta mais como promessa, como aspiração última do ser humano, cujo acesso, no entanto lhe é interditado, uma vez que sempre, em sua fala, há o vestígio do outro. Por isso, na perspectiva derridiana, não se fala várias línguas apenas quando mesclamos línguas nacionais, mas sempre, visto que é preciso se apropriar da fala do outro para poder significar.

Essa sensação de falta faz, segundo Derrida (2001), com que as pessoas construam próteses com o intuito de supri-la ou compensá-la. O autor destaca dois tipos de próteses: (i) a procura de história e de filiação, isto é, a recuperação ou invenção de uma narrativa da história familiar e (ii) a exigência compulsiva de uma pureza da língua, ou seja, a preocupação exacerbada com a correção linguística.

\section{A COLETA DO CORPUS E A METODOLOGIA DE ANÁLISE}

A seleção dos participantes foi definida obedecendo a quatro critérios:

(i) ser brasileiro;

(ii) ser falante de português e de inglês;

(iii) utilizar ambas as línguas em alguma esfera de suas vidas, por exemplo, profissional, familiar, entre outras; e,

(iv) ser escolarizado, uma vez que o relato seria dado por escrito.

No total, foram obtidos nove relatos escritos de bilíngues simultâneos e nove relatos de bilíngues sequenciais, por meio da pergunta: Você se considera bilíngue? Por quê?. Esses sujeitos responderam, no ano de 2011, a essa pergunta por escrito e a partir 
de suas respostas tecemos as análises presentes neste trabalho. Optamos por organizar os participantes desta pesquisa desse modo para que fosse possível contrastar e comparar as respostas obtidas por esses dois tipos de sujeitos bilíngues.

Os sujeitos desta pesquisa foram identificados por nomes fictícios. Os bilíngues simultâneos foram nomeados por nomes que iniciam com a letra $\mathrm{C}$, sendo eles Clara, Caio, Celeste, Caetano, Camila, Canuto, Carla, Carmem e Claudia. Por sua vez, os bilíngues sequenciais têm seus nomes fictícios grafados com a inicial A: Ana, Ângela, Antonio, Armando, Assis, Alice, André, Allan e Augusto.

No exercício da análise, inicialmente, localizamos as representações dos sujeitos sobre o que é ser bilíngue e o que é bilinguismo, pois, a partir dessas, seria possível compreender o fenômeno estudado, uma vez que as representações são:

[...] maneiras socialmente construídas de perceber, configurar, negociar, significar, compartilhar e/ou redimensionar fenômenos, mediadas pela linguagem e veiculadas por escolhas lexicais e/ou simbólicas expressivas que dão margem ao conhecimento de um repertório que identifica o indivíduo e sua relação sócio-histórica com o meio, com o outro e consigo mesmo (FREIRE; LESSA, 2003, p. 174).

A seguir, separamos o conjunto de enunciados de acordo com as representações encontradas e os analisamos quanto à sua posição ideológica e no tocante aos aspectos identitários que podiam suscitar.

Cabe mencionar que, no decorrer das análises, o retorno ao corpus foi constante, assim como o reajustamento dos agrupamentos, considerando a exclusão ou a inclusão de enunciados.

Com a trajetória da pesquisa delineada, temos subsídios para o trabalho com os dados. Dessa maneira, apresentaremos, na próxima seção, a discussão dos resultados a partir da análise do corpus.

\section{ANÁLISE E DISCUSSÃO DOS DADOS}

Nesta pesquisa, frente às respostas obtidas à pergunta "Você se considera bilíngue? Por quê? podemos constatar que dois, dentre os dezoito participantes, um bilíngue simultâneo e um sequencial, não aceitam serem chamados de bilíngues, apesar de utilizarem o português e o inglês em suas interações diárias. Podemos inferir que os enunciados proferidos por Ana e Clara mobilizam uma preocupação em dominar as línguas e, desse modo, utilizá-las com naturalidade: 


\begin{abstract}
Ana: Não. Porque, apesar de me comunicar razoavelmente na língua inglesa, ainda não sou capaz de usá-la com a mesma naturalidade da língua portuguesa.
\end{abstract}

Clara: Não sei, pois creio que não domino nenhuma delas bem e tenho dificuldade com todas. ${ }^{4}$

Ana confere ao seu dizer um sentimento de segurança em relação à sua língua materna, o português, e afirma não experimentar a mesma sensação de conforto em inglês. O enunciador emite, nesse relato, uma ilusão de que tudo o que disser na língua materna é controlável e da ordem do consciente e, assim, pode se expressar com naturalidade. Ana parece esquecer que a língua materna também é um lugar de equívoco e de mal-entendidos percebidos quando se fala, por exemplo, "não foi isso que eu quis dizer" ou outros enunciados dessa ordem.

$\mathrm{Na}$ tessitura do dizer de Ana, pode-se desvelar também um dizer sobre línguas distintas: a língua materna que o sujeito acredita ser completa e transparente e a língua estrangeira que é a língua do desconforto e do estranho. Depreende-se do dizer de Ana que, para ela, as línguas que a constituem são línguas que funcionam separadamente e, sendo assim, são puras e homogêneas. Porém segundo Coracini (2007, p.119), "a língua estrangeira não é um sistema vazio de sentido, pois traz consigo uma carga ideológica que coloca o aprendiz em conflito permanente com a ideologia da língua materna".

Por sua vez, Clara afirma não dominar nenhuma língua. O termo dominar, por si só, já é problemático. Primeiramente, porque uma língua não é passível de dominação, uma vez que os sentidos lhe escapam. Seria como se, ao dominar uma língua, o indivíduo pudesse subjugar aquilo que o subjuga na condição de sujeito. Pode-se dizer, portanto, que dominar uma língua só pode ocorrer de maneira ilusória. Percebe-se, também, que tanto o português como o inglês são para esse sujeito uma promessa, ou seja, línguas sempre desejadas, porém não alcançadas. Clara deseja a língua em sua totalidade e afirma ter dificuldade com inglês e com português por não dominá-las. Esse desejo de domínio parece conduzir a uma possibilidade ilusória de uma identidade fixa e una, na qual não haja tensão ou conflito.

Em contrapartida, dezesseis, dos dezoito, participantes reconhecem legítima a denominação de bilíngue quando se referem a si próprios. Ao discorrerem sobre o

\footnotetext{
${ }^{4}$ Todos os excertos são oriundos das respostas obtidas, durante o ano de 2011, por escrito, a pergunta Você se considera bilíngue? Por quê?.
} 
porquê se consideram bilíngues, foi possível localizar suas representações sobre o que é ser bilíngue e o que é bilinguismo. A representação mais recorrente, dentre as obtidas nesta pesquisa, é a de que o sujeito bilíngue é aquele que se comunica bem ou com naturalidade em ambas as línguas:

Carmem: Sim, sou bilíngue, pois consigo me comunicar tanto oralmente quanto na escrita em ambas as línguas

Angela: Sim, porque gerencio ambas as línguas em todas as situações.

Antonio: Sim, tenho um bom grau de fluência e precisão em mais de uma língua.

Armando: Sim, porque consigo me comunicar e me expressar em duas línguas. ${ }^{5}$

Essas justificativas dão indícios de que esses sujeitos veem a língua, mais uma vez, como um processo consciente e controlável, não subjugado a deslizes, chistes ou lapsos. Além disso, a visão predominante de bilinguismo aqui é focada na proficiência das línguas. Essas posições sobre quem é bilíngue estruturam-se dentro de uma perspectiva que considera apenas aspectos linguísticos para a definição de sujeito bilíngue e bilinguismo, como proposto por Macnamara (1967) e Barker e Prys Jones (1998), entre outros.

Outros sujeitos preferiram distinguir as habilidades da língua, produção oral e compreensão auditiva para autodenominarem-se bilíngues:

Caio: Sim, porque considero que posso me comunicar (verbalmente) suficientemente bem nessas línguas.

Celeste: Sim, porque entendo perfeitamente as duas línguas.

Essas representações de língua, associadas às habilidades, nos levam a crer que a língua é tomada em seu papel instrumental de comunicação, reforçando a noção de exterioridade da língua, isto é, a língua, para esses sujeitos, é um lugar externo a eles e à sua identidade, ou seja, um lugar das necessidades sociais, como se comunicar, ou entender.

Ademais, percebemos, tanto em Caio quanto em Celeste, a interpelação pelo discurso tradicional que considera bilíngue apenas aquele que possui competência linguística equivalente em ambas línguas. Acreditamos que essa concepção, a de

\footnotetext{
${ }^{5}$ Excertos obtidos por meio a resposta, por escrito, à pergunta Você se considera bilíngue? Por quê? durante o ano de 2011.
} 
bilinguismo balanceado, como proposto por Bloomfield (1935), que define bilinguismo como o controle nativo de duas línguas, ainda, vigora entre a sociedade atual e é amplamente utilizada para a definição de bilíngues.

$\mathrm{Na}$ mesma direção, Caetano afirma que se aceitou como bilíngue após um americano afirmar que suas habilidades linguísticas eram superiores se comparadas com bilíngues de pai e mãe. É importante relembrar que Caetano é oriundo de uma família brasileira e é bilíngue simultâneo, pois estudou em uma escola internacional desde a primeira infância.

Caetano: Sim, ao fazer amizade com um americano que trabalhava comigo, e por ele me tratar como igual e me comparar com outros bilíngues de pai e mãe (apontando que minhas habilidades linguísticas eram até superiores) eu me aceitei bilíngue.

Para Caetano aceitar-se como bilíngue, foi necessário o veredito de um falante nativo da língua que não é falada no país que mora. Percebemos, aqui, o papel do outro, falante nativo, no sentimento de pertença que o sujeito atribui ao grupo de bilíngues.

Outra representação bastante recorrente foi a de que o sujeito bilíngue é aquele que adquiriu as duas línguas na primeira infância, sendo expostas a elas desde o nascimento:

Assis: Sim, pelo fato de tanto inglês e português estarem presentes na minha vida desde muito cedo, acredito que posso me considerar bilíngue nesse sentido.

Essa representação parece excluir outros tipos de bilíngues, como o bilinguismo adolescente e o bilinguismo adulto, conforme proposto por Hamers e Blanc (2000). No senso comum, os bilíngues simultâneos são os chamados "bilíngues reais" ou "bilíngues de verdade", como se os demais tipos de bilinguismo não fossem legítimos.

Outro aspecto interessante observado foi à atribuição de pensar por meio de uma das línguas ao fato de ser bilíngue:

Camila: Sim, porque misturo as línguas ao falar, e na maioria das vezes, penso em inglês e fui alfabetizada bilíngue.

Canuto: Sim, porque penso nas duas línguas e, às vezes, confundo as duas. 
Camila afirma pensar em inglês, enquanto Canuto relata pensar nas duas línguas. Nesses recortes, desvela-se a construção de um dizer que remete a uma reprodução de falas, recolhida, pelo sujeito-enunciador, do senso comum, do interdiscurso, e oriunda do discurso pedagógico amplamente pregado no Brasil, que prioriza a oralidade em detrimento de outras habilidades e que dita aos alunos que devem pensar em inglês para serem fluentes.

Outro ponto interessante nos relatos de Camila e Canuto é o fato de que ambos enunciadores atrelam o pensar em determinada língua à ideia de misturar ou mesmo confundir as línguas. Nesses casos, percebemos que Camila e Canuto tomam como suas as palavras de uma voz anônima, a qual se produz no interdiscurso, dessa maneira, apropriando-se da memória que se manifesta em seus discursos. Existe, ainda, no senso comum, certo receio ao bilinguismo, uma vez que é associado à confusão ou mistura de línguas, o que resultaria em baixo desenvolvimento cognitivo.

Historicamente, o bilinguismo foi visto, por educadores, como prejudicial para o desenvolvimento cognitivo da criança. Pesquisas iniciais sobre o tema apontavam o bilinguismo como causa de baixo quociente intelectual, confusão linguística e até mudança de personalidade. Consequentemente, surgiu o mito de que o bilinguismo seria prejudicial ao desenvolvimento cognitivo da criança. Todavia outras pesquisas revelam que uma série de críticas metodológicas pode ser feita a esses estudos iniciais: os participantes bilíngues da pesquisa estavam em situação desigual, se comparados aos monolíngues, em termos socioeconômicos ou de proficiência na língua do teste aplicado. Além disso, muitas vezes, esses testes foram ministrados na língua de menor domínio dos participantes. Em estudos mais recentes, os quais fazem uso de modelos experimentais mais elaborados, essas variáveis foram mais bem-controladas e, com isso, os resultados apontaram uma direção bastante diferente.

Vale ressaltar que, dentre as dezesseis respostas, à pergunta: Você se considera bilíngue? Por quê?, apenas duas remetem a questões não linguísticas para se justificarem como bilíngues:

Alice: Sim, porque além de me comunicar na língua inglesa, ao adquirir outra língua, ainda que sem me dar conta no inícios, passei a incluir diferentes maneiras de "ler" o mundo, ou atribuir sentidos.

André: Sim, por ter vivido em ambas as comunidades e ter presenciados diversas situações linguísticas em ambas as línguas, acredito fazer parte dessa comunidade bilíngue. 
Alice direciona seu olhar a como a língua inglesa lhe proporcionou diferentes formas de atribuir sentido ao mundo. Uma das razões que motiva muitas pessoas a engajarem-se na aprendizagem de uma língua estrangeira é o desejo de ampliar os horizontes culturais. Sendo assim, Alice relata as vantagens associadas ao saber uma língua estrangeira, uma vez que a língua inglesa é encarada, no Brasil, como uma língua superior, mesmo por seu percurso histórico. André, por sua vez, relata que o fato de ter vivido em ambas comunidades linguísticas o caracteriza como bilíngue. Para André, ser bilíngue não está relacionado apenas às línguas envolvidas, mas também ao fato de ter vivido em comunidades nas quais essas línguas eram utilizadas.

Nesse momento, faz-se importante relacionar esses recortes discursivos, que justificam a classificação desses sujeitos como bilíngues, ao conceito de classificação de Moscovici (2003), discutido na seção Representações Sociais deste trabalho. As classificações, segundo o autor, são feitas comparando pessoas a um protótipo aceito como representante de uma classe. Observa-se, a partir dos recortes selecionados, que o protótipo mais aceito para a denominação bilíngue é o de alguém que utiliza as duas línguas com a mesma naturalidade. Classificar, esclarece o autor, implica nomear. Ao nomear esses sujeitos como bilíngues, eles são incluídos em um complexo de termos específicos que o localizam no mundo.

Embora quase todos os participantes aceitem ser chamados de bilíngues, é importante notar que nem todos aceitam sem ressalvas, como observamos nos enunciados a seguir:

Assis: Embora o português seja o idioma predominante na minha vida familiar, pelo fato de tanto inglês e português estarem presentes na minha vida desde muito cedo, acredito que posso me considerar bilíngue nesse sentido. Mas, evidentemente, para certos assuntos, consigo me expressar melhor em minha língua-materna.

Allan: Sim (dependendo da visão do que é ser bilíngue). Apesar de não possuir as mesmas competências nas duas línguas, eu me considero bilíngue.

Augusto: Sim, me considero, pois posso me comunicar em português, inglês e espanhol, claro que cometo erros de pronúncia e erros gramaticais, mas o importante, a meu ver, é transmitir a informação de forma objetiva para que ambas as partes façam cientes do conteúdo do mesmo.

André: Por ter vivido em ambas as comunidades e ter presenciados diversas situações linguísticas em ambas as línguas, acredito fazer parte dessa comunidade bilíngue, apesar de sempre haver alguns espaços em branco a serem completados na segunda língua. Em resumo, ser bilíngue não é uma 
tarefa fácil, pois exige a fluência e eficiência de viver em duas línguas, em dois mundos, não digo perfeitamente, mas próximo do ideal.

Em todos esses recortes, os sujeitos fazem uso de uma adversativa que marca uma tensão e, com isso, uma nova direção argumentativa na textualidade da narrativa, o que faz emergir contradições do interior das formações discursivas: a língua deixa marcas, traços e instaura a falta e o desejo do sujeito de dominá-la por completo, como se isso lhe fosse possível. Todos esses falantes, ao comentarem sobre seu bilinguismo, justificam-se por não ter um controle nativo ou balanceado nas duas línguas, como sugerem as visões tradicionais de bilinguismo. Na verdade, podemos constatar que todos os recortes descritos remetem à visão que cada indivíduo possui de sua bilingualidade, que pode ser mutável e dinâmica de acordo com as situações de bilinguismo que lhe são apresentadas.

André compara ser bilíngue a uma tarefa, que complementa não é fácil, uma vez que exige, nas palavras do participante, viver próximo do ideal em dois mundos. Observamos, aqui, novamente a ideia de ideal, perfeito e de domínio completo. Este mesmo falante também faz referência a espaços em branco em sua vida, como se a vida em uma língua funcionasse de modo autônomo da vida em outra língua. Este dizer está em conformidade com o discurso de Carla que descreve que:

Carla: Tenho déficits culturais e educacionais de ambos os lados, mas isto não me incomoda mais... sei onde achar ajuda quando preciso.

Para Carla, a vida em uma língua a privou de outra vida em outra língua e, com isso, há uma sentimento de que falta alguma coisa, algum espaço a ser preenchido. Carla afirma ainda que consegue contornar essa falta e buscar ajuda quando precisa. Esses recortes argumentam a favor de uma visão tradicional de bilinguismo, que defende a ideia da existência de espaços monolíngues protegidos e, desse modo, estar em um desses espaços faz com que o sujeito se ausente do outro espaço reservado à outra língua e, com isso, há sempre a sensação de que se perdeu algo enquanto se ocupava um dos espaços.

Assim, segundo nosso entendimento, há pelo menos um motivo para esta dificuldade de se ver como bilíngue. Conquanto se observe no Brasil uma crescente valorização da língua inglesa e uma significativa penetração do inglês por meio de músicas e da tecnologia, indivíduos que aprendem inglês não se enxergam como 
bilíngues. Vigora, ainda, no Brasil, o ideal monolíngue e, dessa forma, ser bilíngue exige definições e justificativas, como se nota entre as narrativas de dois participantes:

\begin{abstract}
Ângela: A questão do bilingualismo puro e ou total, em minha opinião, deve ser visto partindo do ponto de vista que um se sentirá bilíngue devido ao nível ideal, e ou desejável, do uso e razão do uso de qualquer idioma. Ou seja, se um acredita que dar instruções básicas em outro idioma é suficiente, e as mesmas funções satisfazem as necessidades de comunicação desejada, o mesmo poderá se considerar bilíngue. Em outras palavras, o sucesso é relativo, pois quem o determina é o próprio falante/aprendiz.
\end{abstract}

André: A palavra "bilíngue" é um pouco traiçoeira. Ser bilíngue, para alguns autores, não significa somente dizer uma porção de vocábulos ou frases em duas línguas, significa conhecer profundamente a cultura da língua em questão e ativar o vocabulário, a frase e a entonação correta para aquela determinada situação.

Nos dizeres de Ângela e André percebem-se claramente as várias vozes constitutivas de seus discursos. Ângela, inicialmente, tenta marcar sua voz com "em minha opinião", porém há um deslize de sentido e em seguida faz uso de "um" para fazer alusão a uma categoria, ao sujeito bilíngue. Há ainda o discurso científico que está implícito em seu dizer, quando traz à tona as necessidades de comunicação.

André, por sua vez, ao trazer as vozes de outros autores, dá credibilidade ao seu discurso. Esse movimento dialógico auxilia na construção de seu ponto de vista. André traz essas vozes e se une a elas, utilizando-as como um argumento de autoridade.

A análise do corpus desta pesquisa mostra que o discurso científico, ora explícito ora implícito, foi um recurso importante para a definição de bilíngue por parte dos participantes deste estudo. Os conceitos de bilinguismo, sustentados pelos sujeitos, moveram-se dentre as concepções clássicas de bilinguismo, que enfocam o domínio balanceado das habilidades da língua.

\title{
6. TESSITURAS FINAIS
}

Inicialmente, ao decidirmos que teríamos nove sujeitos bilíngues simultâneos e nove sequenciais entre os participantes desta pesquisa, acreditávamos que encontraríamos diferenças, entre os dois grupos, no que concerne às relações destes com as línguas que os constituem e consigo mesmos. O exercício desta pesquisa nos mostrou o contrário: as dúvidas, os conflitos e as questões identitárias mobilizadas 
foram bastante semelhantes, o que nos faz concluir que a experiência de ser/estar entre línguas não é tão facilmente mensurável; antes, não passa de ilusão, porque, a todo o momento, o sujeito se vê frente ao desconhecido na língua que pensa ser sua, ao inesperado que não se quer enfrentar ou ao mal dito que se deseja não ter dito.

No Brasil, constatamos uma valorização cada vez maior da língua inglesa e uma visível penetração do inglês. Nessa direção, Moita Lopes (2004) argumenta que o inglês é necessário para compreender o funcionamento do discurso da vida social contemporânea, uma vez que as mudanças culturais, econômicas, sociais e tecnológicas inicialmente circulam em inglês. No entanto, vigora, ainda, no Brasil, o ideal monolíngue. Com isso, ser bilíngue exige definições e justificativas como percebemos entre as respostas dos participantes, que tentam buscar, na teoria, explicações para a aceitação de sua condição. É como se o sujeito não fosse autorizado a falar sobre sua condição de bilíngue, o que faz com que procure, em enunciadores que considere autorizados, uma justificativa para seu sentir ou pensar. Verificamos um deslocamento para a posição que o falante ocupa na sociedade, o que divide os sujeitos em autorizados ou não autorizados a discorrer sobre o tema.

Ademais, percebemos a dificuldade em se classificar bilíngue, que decorre também da representação social que se tem a respeito do bilinguismo. Essa classificação é feita ao se comparar pessoas a um protótipo aceito como representante de uma classe, no caso, a de indivíduos que falam duas línguas. Observamos, nesta pesquisa, que o protótipo mais aceito para a denominação bilíngue é a de alguém que utiliza as duas línguas com a mesma naturalidade. Somando-se a isso, a língua estrangeira não é um sistema vazio de sentido, pois traz consigo uma carga ideológica que coloca o aprendiz em conflito permanente com a ideologia da língua materna. Outros sujeitos, ao narrarem aspectos relacionados à sua bilingualidade, apresentam, dentro de suas formações discursivas, marcas de tensão que demonstram que a língua deixa marcas, traços e instaura a falta e o desejo do sujeito de "dominá-la" por completo, como se isso lhe fosse possível. 


\section{REFERÊNCIAS}

BAKER, C. \& PRYS J. Encyclopedia of Bilingualism and Bilingual Education. Multilingual Matters, 1998.

CAVAlli, J. Classe $\mathrm{C}$ investe nos cursos de inglês. Diário Catarinense. Florianópolis, 25 jun. 2012.

Disponível em: $<$ http://diariocatarinense.clicrbs.com.br/sc/economia/noticia/2012/06/classe-c-investenos-cursos-de-ingles-3800438.html>. Acesso em: 02 set. 2012.

BLOOMFIELD, L. Linguistic aspects of science. Philosophy of Science 2: 499-517. Reprinted in Hockett, 1970, pp. 307-321, 1935.

CAVALCANTI, M. Estudos sobre educação bilingüe e escolarização em contextos de minorias lingüísticas no Brasil. D.E.L.T.A., 15, 1999, p. 385 - 417.

CORACINI, M. A celebração do outro - arquivo, memória e identidade: línguas (materna e estrangeira), plurilinguismo e tradução. Campinas: Mercado de Letras, 2007.

DERRIDA, J. O monolinguismo do Outro ou a prótese da origem. Tradução de Fernando Berardo. Porto: Campo das Letras, 2001.

FREIRE, M.; LESSA, A. Professores de Inglês da rede pública: suas representações, seus repertórios e nossas interpretações. IN: BARBARA, L. e RAMOS, R. (org.) Reflexão e ações no ensino-aprendizagem de línguas. Campinas: Mercado de Letras, 2003.

GARCÍA, O. Bilingual education in the 21st century: A global perspective. Oxford: Wiley-Blackwell, 2009.

GROSJEAN. F. Life with two languages: An introduction to bilingualism. Cambridge, Mass: Harvard University Press, 1982.

HAMERS, J.; BLANC, M. Bilinguality and Bilingualism. Cambridge: Cambridge University Press, 2000.

HELD, D.; MCGREW. A. Modernity and its Futures. Cambridge: Polity Press, 1992.

HEYE, J. Considerações sobre bilinguismo e bilingualidade: revisão de uma questão. Revista paLavra. Rio de Janeiro: PUC-Rio, v 11, 2003, p.p. 30-38.

JODELET, D. Representações Sociais: um domínio em expansão. Rio de Janeiro: EDUERJ, 2001. 
LORDELO, C. e SILVA, C. A classe C cruza a fronteira. Estadão.com.br/educação. São Paulo, 13 dez. 2011. Disponível em: <http://www.estadao.com.br/noticias/vidae,aclasse-c-cruza-a-fronteira,810143,0.htm>. Acesso em: 02 set. 2012.

MACNAMARA, J. Bilingualism in the modern world. 23 J. of social issues, 1967.

MAHER, T. O dizer do sujeito bilíngüe: aportes da sociolingüística. Anais do Seminário Desafios e Possibilidades na Educação Bilíngüe para Surdos. Rio de Janeiro: INES \& Editora Líttera Maciel, 1997.

T. Do casulo ao movimento: a suspensão das certezas na educação bilíngüe e intercultural. In: CAVALCANTI, M. C.; BORTONI-RICARDO, S. M. (Orgs.). Transculturalidade, linguagem e educação. Campinas, SP: Mercado de Letras, 2007, p.67-94.

MOITA LOPES, L.P. A nova ordem mundial, os PCNs e o ensino de inglês no Brasil: a base intelectual para uma ação política. IN: BARBARA,L; RAMOS,R de C.G. (Orgs.). Reflexões e ações no ensino aprendizagem de línguas. São Paulo. Mercado das Letras, 2004.

MOSCOVICI, S. A Representação Social na Psicanálise. Rio de Janeiro; Zahar, 1978. Vozes, 2003.

S. Representações sociais: investigações em psicologia social. Petrópolis:

NICACIO, A. A classe C vai ao paraíso. Isto é independente. São Paulo, 20 ago 2012.

Disponível em: <http://www.istoe.com.br/reportagens/96820_A+CLASSE+C+VAI+AO+PARAISO>. Acesso em: 02 set. 2012.

WEI, L. Dimensions of Bilingualism. In: WEI, L. The Bilingualism Reader. London; New York : Routledge, 2000. 